\title{
Market Integration in the International Market of Soybeans: Are GM Soy and Non-GM Soy Markets Integrated?
}

\author{
Guillermo Andrés Larre ${ }^{1}$ \\ ${ }^{1}$ Agricultural Information Institute (AII), The Graduate School of the Chinese Academy of Agricultural \\ Sciences (GSCAAS), Beijing, P.R. China \\ Correspondence: Guillermo Andrés Larre, Agricultural Information Institute (AII), The Graduate School of the \\ Chinese Academy of Agricultural Sciences (GSCAAS), Beijing 100081, P.R. China. E-mail: \\ guillermolarre@outlook.com
}

Received: June 17, 2019

doi:10.5539/jas.v11n15p14
Accepted: July 27, $2019 \quad$ Online Published: September 15, 2019

URL: https://doi.org/10.5539/jas.v11n15p14

This research was financed by the Chinese Scholarship Council (CSC).

\begin{abstract}
This paper aims to study market integration in the international trade of soybeans from 1999 to 2019. The hypothesis is that the market remained integrated between genetically modified (GM) and non-GM soy, even after stringent regulations against GM soy in major importers starting in 1999. Using FOB prices from major exporters of GM soy (USA and Argentina) and non-GM soy (Brazil), I test for market integration with cointegration analysis and Granger causality tests. All tests show that the market between all three exporters remained integrated throughout the sample period. Furthermore, Granger causality tests show that USA remains the sole price leader. Short run elasticities for reactions to American price changes in Brazil and Argentina are 0.33 and 0.25 , respectively. The results validate the Law of One Price and inform policy decisions and forecasts efforts in this valuable commodity.
\end{abstract}

Keywords: market integration, soybeans, cointegration, granger causality, structural breaks

\section{Introduction}

The purpose of this paper is to study the horizontal spatial transmission for the international market of soybeans over the period 1999-2019, in order to check for market integration under the Law of One Price (LOP), as well as report the elasticities and the directionality of the price transmission.

The LOP is the basic foundational notion in economics that the prices of equal goods in different locations within an open market will tend to equalize, as market agents make use of arbitrage opportunities to close existing gaps. When markets share a price under LOP they are said to be integrated. Product differentiation can cause deviations from LOP (Pippenger \& Phillips, 2008). Such disruptions to trade have occurred in soybeans due to the development of genetically modified (GM) soy, where differences regarding the legal status of GM soy in major exporters and importers has led to the possibility of a rift between a GM soy and a non-GM soy markets.

First developed in 1996, GM soy quickly became the dominant form in major producers and exporters, including USA, Argentina, and Paraguay, where by 2016 it accounted for $94 \%, 100 \%$, and $96 \%$ of total production, respectively. However, Brazil, the single biggest exporter, still produces a majority non-GM crop, with $32 \%$ GM cultivation the same year (ISAAA).

Moreover, the EU, who collectively make up the second largest importer, has banned trade of GM soy varieties, starting in 1999 with a moratorium on trade of GM food, fixed in place by stringent new regulations in 2003, and then formalized in bans across numerous member countries. Also China, currently the biggest importer by a large margin, has placed stringent regulations on GM soy trade, including prohibition of direct consumption, all imports are exclusively for industrial use, and long delays in approving individual GM varieties. Because each new GM event requires each separate country's approval before it can be freely traded, this causes further trade disruptions as specific new events are approved in exporting countries but not yet in the importers. 
By testing for market integration between major exporters Brazil, USA, and Argentina, who altogether account for nearly $90 \%$ total world supply, price transmission between GM and non-GM soy prices can be tested, i.e. market integration between GM and non-GM soy.

Market integration under LOP assumptions will be checked for through cointegration analysis. Then, if spatial transmission is found, the dynamics of price leadership will be studied through Granger causality. This provides further proof of market integration (Ravallion, 1986). The hypothesis is that the international market for soybeans is highly integrated even through the period of highest volatility and the growing trend in GM bans. In addition, I expect USA to appear as price leader, given the traditional role of that the prices in the Chicago Board of Trade (CBOT) have played as reference prices for the market. However, I also expect the possibility that Brazil might have assumed price leadership as well, given their growing importance in the market, surpassing USA as main exporter in 2012. This study was done using STATA 15.

The chosen period involves a time of significant price volatility, as American FOB prices went from a minimum of 152 USD near the start of the period in October 2001, to experience several dramatic peaks starting in 2007 with a maximum of 628 USD in August, 2012, and finish at the range of low 300s USD by the end of the period. This volatility and shifts in trend and levels might surface in the form of a structural break in the time series analysis.

The results aim to validate the LOP, and do so in the context of an exported commodity, a market heavily distorted by trade regulation, and over a period of wide price fluctuation. Furthermore, given the relevance of this commodity for the world economy, I hope to provide useful information on the dynamics of price transmission for agricultural commodities, that might assist forecast efforts and policy design.

\section{Literature Review}

The transmission of international commodity prices has traditionally been studied under the theoretical framework of the LOP, which states that markets that trade tend to show equal prices for equal products, within a certain rate measured by the efficiency of the transmission (for a full review, see Fackler \& Goodwin, 2001). It was originally tested for with lineal correlations, however, when innovations related to cointegration analysis came about, the LOP came under intense criticism because many studies found no supporting evidence for it. Ardeni (1989) found that under cointegration the LOP did not stand empirical tests, as permanent deviations to it were apparent and widespread. Later studies have salvaged the LOP by introducing conditions that need to be checked for, in order to ensure methodological robustness. Pippenger and Phillips (2008) identify such conditions, one of them being using identical products, which has been broken in the international soybeans market by the advent of GM soy.

For price transmission, there is a large literature focused on horizontal spatial transmission, mostly in areas such as international financial markets and commodity trade, in agriculture and energy. A key concept in horizontal spatial transmission is that of market integration. Markets are said to be integrated when co-movements of prices are observed in them, that is, price information is transmitted between them. Since the influential work of Ardeni (1989), the academic literature has taken to the presence of cointegration as sufficient proof that market integration exists (Listorti \& Esposti, 2012). This is because a stable (nonstationary) long-run relationship is both a requisite for the validity of LOP as well as the presence of cointegration (Ardeni, 1989). Ravallion (1986) and Garbade and Silver (1978) have provided alternative methods for establishing market integration, based on Granger causality and weak exogeneity tests.

\subsection{Studies on Soybeans International Market Integration}

Uri, Chomo, Hoskin, and Hyberg (1993) tested for market integration in soybeans, soy meal, and soy oil international markets, using Granger causality. They test the prices of American, Brazilian, and EU products pairwise, and establish market integration in all cases. However, it should be noted this study was done before the development of GM soy and its possible effects on market integration.

For price transmission, Machado and Margarido (2001) study the Argentinian, American and Brazilian FOB prices as well as Rotterdam (EU) CIF price series using ARIMA deseasoning and Granger Causality on a vector autoregression (VAR) on log-levels, and find that both Brazilian and Argentinian prices are Granger-caused by European CIF prices, whereas American prices are not related to any of the other series. In a similar later study (Machado \& Margarido, 2004) they find evidence for transmission from USA to Argentina and Brazil, albeit weaker than the responses to EU prices. It is worth noting that these studies were done before the EU banned the trade on GM soybeans and before the dramatic rise of Chinese imports, so the EU was back then still the most important destination for Argentinian and Brazilian soybeans. In addition, these studies were conducted before it 
was widely understood that Granger Causality is not robust to the presence of orders of integration as well as cointegration in the underlying VAR when using the true order of lags (Toda \& Phillips, 1994).

Margarido, Turolla, and Bueno (2004) used cointegration, Granger Causality, and other methods to characterize the seasonal international price transmission for soybeans using Argentinian, American and Brazilian FOB prices as well as Rotterdam (EU) CIF prices. They find that shocks in American and European prices transmit to Brazilian prices, whereas Argentinians only respond to American ones, and American prices are only weakly affected by Brazilians. Overall the short-run reactions appear to be slow. They offered the absence of trade due to EU regulations on GM as the explanation for the lack of Argentinian response to EU shocks, and the seasonal symmetry between USA and Brazil as the reason behind the small reactions observed in USA to Brazilian prices.

More recent studies of price leadership have tended to focus in futures markets. Christofoletti, Silva, and Mattos (2012) studied market integration for both spot and future soybeans prices between USA, China, Brazil, and Argentina, using cointegration analysis on daily prices from 2002 to 2011, split into subperiods to control for structural breaks. Their results show that the relationship has changed over time, interestingly, both USA and Argentina are shown to no longer be integrated to the other prices during and after the food crisis. These results could indicate a rift between GM soy and non-GM soy markets.

Han, Liang, and Tang (2013) used cointegration to study price discovery between CBOT and the Dalian Commodity Exchange (DCE) in China from 2002 to 2011. They found bidirectional effects, lead by CBOT who has the greater impact. Li and Hayes (2016) studied future prices in China, USA, and Brazil, from 2005 to 2015, using non-linear cointegration and weak exogeneity, as well as sample splitting. They found instead that CBOT prices retain single leadership over the futures prices market, although there is a weakening trend in the link, and in addition it is affected by seasonal variations with Brazil adopting temporal leadership during its marketing season. Liu et al. (2015) used the generalized autoregressive conditional heteroskedasticity-generalized error distribution (GARCH-GED) model to study future prices volatility transmission between CBOT and DCE from 2006 to 2012, with sample splitting to account for the 2008 subprime crisis, and found CBOT prices no longer lead DCE future prices for non-GM soy after the break. Finally, Lee, Lin, and Liao (2013) used a cointegration representation with GARCH and sample splitting for structural breaks to study price leadership between CBOT and DCE in several commodities futures prices, including soybeans, from 2002 to 2011. For soybeans, they found CBOT leading DCE in long-run adjustments, however for short-run transmissions the opposite is true.

It can be seen that the existing literature on this subjects, except futures prices, is quite dated, for market integration preceding the development of GM soy and for price transmission being before the advent of stringent GM soy regulation and market changes in the last 15 years. Regarding price leadership in this market, the consensus among the literature reviewed is that USA is the traditional price maker, thanks to the leading role played by CBOT prices, and Brazil and Argentina are price takers.

However, the development of GM soy and the subsequent regulations on its trade, the growing role of Brazil in export trade, as well as findings on futures prices about a weakening trend in American price leadership, all prompt the need to update the study of market integration and price transmission in the international market for soybeans, with more recent data that might reflect the changing trade patterns in the last 20 years.

\section{Data}

The price series to be compared are the spot prices of Brazil, USA, and Argentina soybeans export prices. These three exporters altogether account for close to $90 \%$ of total international supply during the chosen period. The price series start in October, 1999, and end in February, 2019, with a total of 233 observations. Their natural logarithms are taken, to provide of ease of interpretation of some of the results.

The price series used were as provided in Table 29 of the publication Oilseeds: World Market and Trade over many numbers (1999-2019), published by the United States Department of Agriculture (USDA). For Brazil, Brazil Paranagua FOB price is used; for USA, U.S. NO.1 Yellow Cash Central Illinois; and for Argentina, the Argentina Up River FOB. All prices are measured in US dollars. 


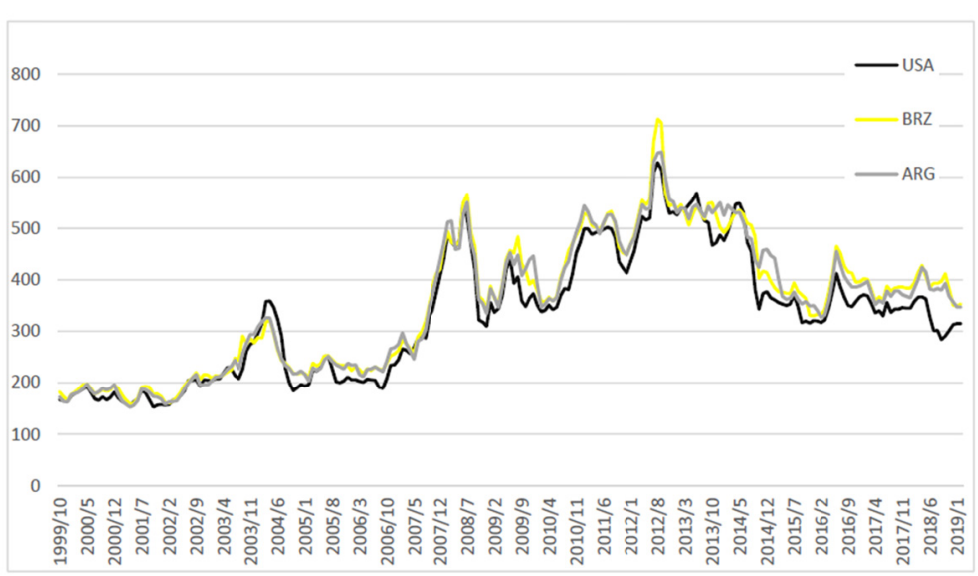

Figure 1. Argentinian, American and Brazilian FOB prices for soybeans, in USD (1999-2019)

The period 1999-2019 saw agricultural commodity prices experience great volatility, with two distinct spikes in the years 2008 and 2012, as part of a general worldwide food-items price inflation. A new development by the end of the period was the growing spread between the export prices, as a large temporary malus to the American soybeans export price appeared as a result of trade frictions with China. American prices are, on average, the cheapest of the three main exporters throughout the whole period, however, during the second semester of 2018 this spread was momentarily much more pronounced than in the rest of the period under study.

\section{Methodology}

Market integration will be tested for using Johansen's method for cointegration. Cointegration analysis begins by testing the selected variables for unit roots using an Augmented Dickey-Fuller (ADF) test (Said \& Dickey, 1984), in order to test a null hypothesis of nonstationarity against an alternative hypothesis of stationarity or trend-stationarity. This further involves a test to their first level difference in order to clarify the exact order of integration, if the first test fails to reject the null hypothesis but the test to their first differences does not, then the series is taken to be nonstationary with first level differences stationarity, that is, I(1). If the second test fails too, then the series must be an explosive process (higher than first order integration), and would require transformation.

The following step is to use the widely known Johansen procedure (Johansen, 1995) in order to sequentally test the null hypothesis of no cointegration starting from 0 and increasing until the null hypothesis is rejected, or the amount of variables is reached. If at any point before that the null hypothesis is rejected, then cointegration is validated and the amount of cointegrating vectors shown. This way, the procedure tests for both the presence and number of cointegrating vectors between the variables.

If, as expected per previous studies, the time series for the selected prices turn out to be I(1) per ADF results, and a cointegrating relationship is detected by the Johansen test, then the variables can be fitted into a Vector Error Correction Model (VECM) that follows the form:

$$
\Delta p_{t}=c+\Pi E C M_{t-1}+\sum_{j=1}^{l} \Gamma_{j} \Delta p_{t-j}+\varepsilon_{t}
$$

Where, $\Pi$ and $\Gamma$ are matrixes, and $p, c$, and $\varepsilon$ are nx 1 vectors, $l$ is the autoregressive order such that $l \geq 1$, and $\varepsilon$ residuals are assumed independently and identically distributed (iid).

The ECM term represents a lagged error correction term, measuring the stationary linear combination of the cointegrated variables, that reintroduces the long term dynamics that were lost by differencing the variables.

$$
E C M_{t-1}=p_{1 t-1}-\beta_{0}-\beta_{1} p_{2 t-1}
$$

In fact, it is simply the residuals from a linear regression of the terms, however, by the properties of cointegration, it should not carry the nonstationarity of the original level variables. Its lag is set at 1 per model definition (Johansen, 1995).

When estimating the VECM representation, coefficients for the lagged differences of the variables then provide the short-run relations between them. If the variables are in log-levels, then the significant coefficients can be read directly as elasticities. The coefficients of the error correction term, in turn, provide the long-run adjustment of the variables to equilibrium, implied by the cointegration. 
The final step of the study will be running Granger Causality tests under the Toda-Yamamoto procedure (Toda \& Yamamoto, 1995), to look at directionality of the horizontal price transmission and provide further proof of market integration. The null hypothesis implies that lagged coefficients for a variable do not add power to explaining the variation of another variable solely based on its own lagged value. On the other hand, rejecting the null, i.e. declaring Granger causality, means that knowing and including the lagged values of the Granger-causing variable can enhance our forecasting models for the Granger-caused variable. This is because there is a tendency for the variation on the Granger-causing variable to precede similar variation in the Granger-caused one.

In the context of this study, it is critical to note that existing literature has proven that it is best not to run Granger causality tests on coefficients obtained through a VECM model. This is because in these cases the pretesting for unit roots and cointegration causes the distribution of the test statistics not to properly converge to a chi-squared distribution under the null. As a result, estimates are unaffected but critical values are unreliable, and there is a severe increase to Type I error probabilities (Toda \& Phillips, 1994; Dolado \& Lütkepohl, 1996).

In order to address these issues, Toda and Yamamoto (1995) developed a method for testing Granger Causality over VAR models that may be integrated or cointegrated. It does not require pretesting for integration and cointegration, and thus bypasses the above-mentioned problems related to unit root and cointegration.

Instead, it relies on intentionally overfitting a VAR on levels model with as many extra lags as orders of integration the variables may possibly have. However, the coefficients of the extra lags are not used as part of the Wald test in the following step. The equations for Granger Causality thus remain the same. They prove that such a model provides a robust basis for Wald-testing the resulting coefficients, other than those of the extra lags which are not included in the test and assumed to be zero.

The authors realize that this method suffers from inefficiency due to the intentional overfitting in lag order, however they believe this inneficiency is preferable to the problems that arise with alternative methods. Both Zapata and Rambaldi (1997), and Clarke and Mirza (2006), when directly comparing the properties of the likelihood ratio test as used under Johansen's method, to the Toda-Yamamoto method with extra lags augmented-Walt tests, agree that the latter is far preferable to the former, unless the sample size is very small (less than 50 observations). Additionally, they prove the Toda-Yamamoto procedure is robust to a variety of situations such as stability conditions, cointegration rank, and many other forms of underlying model misspecification.

\subsection{Identification of Structural Break}

Johansen's method suffers from very low power when faced with time series whose true underlying model have an unknown structural break in levels (constant) or regime (constant and slope) of the cointegrating vectors or the trend component, as shown by Gregory and Hansen (1996, 2009).

They propose instead three possible residuals-based tests with a null of no cointegration and an alternate hypothesis of cointegration with a single structural break point of unknown timing. These tests are multivariate generalizations of the modified ADF, Za and Zt tests (Zivot \& Andrews, 1992). The purpose of the Gregory-Hansen tests is to find the break point under cointegration by repeatedly running ADF, Za or Zt tests for all points and choosing the one that minimizes the modified statistics. They provide the asymptotic distributions and critical values for up to four regressors.

However, it is worth noting that the Gregory-Hansen tests are powerful against the alternate of cointegration without a structural break as well, just like the unmodified ADF (Gregory \& Hansen, 2009). If the purpose is to test for structural break under cointegration alone, then only the case where ADF fails to reject the null while Gregory-Hansen does reject it, would provide proof of the presence of a structural break. Otherwise, Gregory-Hansen does not provide conclusive proof that the true model is one of cointegration with a structural break.

If structural breaks have been identified, dummy variables will be used to control for their effects (Dawson, Sanjuan, \& White, 2006; Dawson \& Sanjuan, 2006).

\section{Results and Discussion}

The ADF results for all three series shows they are all I(1) nonstationary, since the tests fail to reject the null of nonstationarity at the levels, but do reject it at the first difference. 
Table 1. ADF results

\begin{tabular}{lll}
\hline Variable & Test Stat. & p-value \\
\hline ARG & -1.723 & 0.4193 \\
$\Delta$ ARG & -11.397 & $0.0000^{*}$ \\
USA & -1.753 & 0.4038 \\
$\Delta$ USA & -10.279 & $0.0000^{*}$ \\
BRZ & -1.658 & 0.4527 \\
$\Delta$ BRZ & -11.800 & $0.0000^{*}$ \\
\hline
\end{tabular}

Note. ADF results at log-levels and first differences. $\left(^{*}\right)$ is for rejections of the null of unit root.

Since the variables are all I(1), the next step is to test for cointegration, in order to decide if the better fit is a VECM or a VAR in differences. I use Gregory-Hansen tests for the null of no cointegration against a null of cointegration with a single structural break, with 2 optimal lags chosen through AIC (Akaike Information Criteria). The result of the test based on ADF was failure to reject the null of cointegration with a regime break in July, 2009. The date corresponds to a second short peak after the initial rise and drop in the 2007-2008 period.

Table 2. Gregory-Hansen modified ADF test result

\begin{tabular}{llllll}
\hline & Breakpoint & Test Stat. & $1 \%$ Crit. Value & $5 \%$ Crit. Value & $10 \%$ Cr. Value \\
\hline ADF & 118 & $-7.29^{*}$ & -5.97 & -5.90 & -5.23 \\
\hline
\end{tabular}

Note. $(*)$ is for rejection of the null of no cointegration.

In order to further test the break point, Johansen tests were run on two models, where one was fit with a dummy variable to account for the break and one without it, and then compare the results. Dawson, Sanjuan, and White (2006) and Dawson and Sanjuan (2006) have proven the validity of this method. The results, listed in Table 3, show that per our expectations, Johansen's procedure fails to detect cointegration without the break, whereas two cointegrating vectors were found with the break placed inside the model.

Table 3. Johansen method results

\begin{tabular}{|c|c|c|c|c|c|}
\hline \multirow{2}{*}{ Rank } & \multirow{2}{*}{ Critical-value } & \multicolumn{2}{|c|}{ Without Break } & \multicolumn{2}{|c|}{ Including Break } \\
\hline & & Eigenvalue & Trace & Eigenvalue & Trace \\
\hline 0 & 29.68 & & 95.6576 & & 96.1373 \\
\hline 1 & 15.41 & 0.28121 & 19.3861 & 0.28142 & 19.7953 \\
\hline 2 & 3.76 & 0.06431 & 4.0320 & 0.06762 & $3.6224 *$ \\
\hline 3 & & 0.01730 & & 0.01556 & \\
\hline
\end{tabular}

Note. Johansen test for cointegration on two models, one that includes a structural break at July 2009 and one that ommits it. Both tests used 2 lags and the same sample. $(*)$ is for first non-rejection of the null

When including the dummy for structural break according to the results of the Gregory-Hansen test, the resulting model has two cointegrating vectors, the maximum possible in a three variable model, and this is an indication of the stability and integration of the long-run relationship between the price series, i.e. the international market of soybeans (Listorti \& Esposti, 2012).

The next step of this study is to fit a VECM model to capture the short run and long run dynamics as well as provide information for the Granger Causality tests in later steps, since it reinforces the causal relationship found in those tests. The model includes two dummy variables, one for seasonal variations and one for the structural break in July, 2009, as identified by the Gregory-Hansen test.

Table 4 lists the results of the VECM model for the equation. The single relevant short run elasticities are those for lagged differences of American prices. They show a $1 \%$ increase in the American FOB price will cause a $0.33 \%$ increase in Brazilian price and a lower $0.25 \%$ increase for Argentinian prices within one month. 
Table 4. VECM results

\begin{tabular}{|c|c|c|c|c|c|c|}
\hline$\Delta \mathrm{ARGt}$ & Coef. & Std. Error & $\mathrm{z}$ & $\mathrm{P}>\mathrm{Z}$ & \multicolumn{2}{|c|}{ 95\% Confidence Interval } \\
\hline cel & -0.3088 & 0.1105 & -2.79 & $0.005^{*}$ & -0.5254 & -0.0922 \\
\hline ce2 & 0.0066 & 0.0649 & 0.10 & 0.918 & -0.1206 & 0.1339 \\
\hline$\Delta \mathrm{ARG}$ t-1 & 0.2430 & 0.1405 & 1.73 & 0.084 & -0.0324 & 0.5185 \\
\hline$\Delta \mathrm{USA} \mathrm{t}-1$ & 0.2531 & 0.1037 & 2.44 & $0.015^{*}$ & 0.0498 & 0.4564 \\
\hline$\Delta \mathrm{BRZ} \mathrm{t}-1$ & 0.2122 & 0.1336 & -1.59 & 0.112 & -0.4741 & 0.0497 \\
\hline season & 0.0050 & 0.0083 & 0.60 & 0.546 & -0.0112 & 0.0213 \\
\hline break & -0.0139 & 0.0093 & -1.49 & 0.137 & -0.0322 & 0.0044 \\
\hline const. & 0.0009 & 0.0090 & 0.913 & 0.913 & -0.0166 & 0.0186 \\
\hline$\Delta$ USA t & Coef. & Std. Error & $\mathrm{Z}$ & $\mathrm{P}>\mathrm{Z}$ & \multicolumn{2}{|c|}{ 95\% Confidence Interval } \\
\hline cel & -0.3481 & 0.1067 & -3.26 & $0.001 *$ & -0.5573 & -0.1389 \\
\hline ce2 & 0.1934 & 0.2040 & 0.95 & 0.343 & -0.2064 & 0.5933 \\
\hline$\Delta \mathrm{ARG} \mathrm{t}-1$ & -0.2394 & 0.2560 & -1.59 & 0.350 & -0.7413 & 0.2625 \\
\hline$\Delta$ USA t-1 & 0.6957 & 0.1486 & 4.68 & $0.000 *$ & 0.4044 & 0.9871 \\
\hline$\Delta \mathrm{BRZ} \mathrm{t}-1$ & -0.0663 & 0.2326 & -0.29 & 0.775 & -0.5223 & 0.3896 \\
\hline season & -0.0047 & 0.0137 & -0.35 & 0.729 & -0.0316 & 0.0221 \\
\hline break & -0.0199 & 0.0170 & -1.17 & 0.240 & -0.0533 & 0.0133 \\
\hline const. & 0.0064 & 0.0089 & 0.72 & 0.472 & -0.0111 & 0.0240 \\
\hline$\Delta B R Z$ t & Coef. & Std. Error & $\mathrm{z}$ & $\mathrm{P}>\mathrm{Z}$ & \multicolumn{2}{|c|}{$95 \%$ Confidence Interval } \\
\hline ce1 & -0.2104 & 0.0970 & -2.17 & $0.030 *$ & -0.4007 & -0.0200 \\
\hline ce2 & -0.2798 & 0.1856 & -1.51 & 0.132 & -0.6437 & 0.0839 \\
\hline$\Delta$ ARG t-1 & -0.0989 & 0.2329 & -0.42 & 0.671 & -0.5556 & 0.3576 \\
\hline$\Delta$ USA t -1 & 0.3380 & 0.1352 & 2.50 & $0.012 *$ & 0.0730 & 0.6031 \\
\hline$\Delta \mathrm{BRZ} \mathrm{t}-1$ & -0.0712 & 0.2116 & -0.34 & 0.737 & -0.4861 & 0.3436 \\
\hline season & 0.0268 & 0.0124 & 2.15 & $0.031 *$ & 0.0024 & 0.0513 \\
\hline break & -0.0163 & 0.0154 & -1.05 & 0.292 & -0.0466 & 0.0140 \\
\hline const. & -0.0042 & 0.0081 & -0.52 & 0.603 & -0.0202 & 0.0117 \\
\hline \multicolumn{4}{|c|}{$\mathrm{ce} 1=0.2086+\mathrm{ARG}+\mathrm{USA}-1.038 \mathrm{BRZ}$} & \multicolumn{3}{|c|}{$\mathrm{ce} 2=0.5438+\mathrm{USA}-1.104 \mathrm{BRZ}$} \\
\hline
\end{tabular}

Note. VECM results for Argentinian, American, and Brazilian prices, in that order. Cointegrating equations included at the bottom. (*) for p-values significant under $5 \%$ level of confidence.

The last step of this study is to run the Toda-Yamamoto procedure for the Granger Causality test of the cointegrated variables. AIC produced lag order 2 for the underlying VAR model, however an extra lag was required in order to address autocorrelation in the residuals, resulting in a VAR(3+1) underlying VAR model.

The results of the Granger Causality test show that both Argentina and Brazil are unidirectionally Granger-caused by United States, at 5\% confidence level, per my expectations according to relevant literature. This reflects the traditional role as price maker that USA has had on the international soybeans market, with the CBOT prices acting as the reference prices for the market, as already identified by several studies (Machado \& Margarido, 2004; Margarido, Turolla, \& Bueno, 2004; Li \& Hayes, 2016).

An additional possible source of Granger causality is found for Argentina from Brazil, which must have surfaced in the period under study. This could be explained by the dynamics of seasonal variation (Margarido, Turolla, \& Bueno, 2007). However, that result only arises at $10 \%$ confidence level, so it is clear that despite becoming the main exporter since 2012, Brazil has not become a price leader in the market.

Table 5. Granger Causality tests results

\begin{tabular}{lll}
\hline Variable & Excluded & $\mathrm{p}$-value \\
\hline Argentina & Brazil & 0.065 \\
Argentina & USA & $0.046^{*}$ \\
Brazil & Argentina & 0.716 \\
Brazil & USA & $0.044^{*}$ \\
USA & Argentina & 0.421 \\
USA & Brazil & 0.387 \\
\hline
\end{tabular}

Note. Granger Causality test results obtained through Toda-Yamamoto method. $\left({ }^{*}\right)$ for p-values significant under $5 \%$ confidence level of confidence. 


\section{Conclusion}

This study seeks to characterize the international price transmission of exports of soybeans, in order to check for market integration between GM and non-GM soy varieties. I first used cointegration analysis which proved the international market for soybeans has been well integrated between the three major exporters Brazil, USA, and Argentina over the last two decades. This shows that GM and non-GM soy still share price information and there has not yet been a split between these two markets. This has wide implications for price forecasts and policies. It shows, for example, that market analysis and forecasts for exclusively GM soy exporters like USA and Argentina should still track developments ocurring in exclusively non-GM markets like the EU.

It also showed Argentinian and Brazilian prices are significantly affected in the short-run by American prices, with $0.33 \%$ elasticity over a one month lag for Brazil, which is higher than the $0.25 \%$ for Argentinian prices. As a result Brazilian prices are more sensitive in the short run to American price changes, than Argentinian prices are.

Then the Toda-Yamamoto procedure for Granger Causality, showed that USA has retained price leadership throughout the period. Against expectations Brazil has largely remained a price taker, despite it becoming the main exporter in 2012 by a widening advantage. It seems that despite the changes in the market in the last 20 years, CBOT prices are still the undisputed reference for traders in both GM and non-GM varieties.

From a theorical point of view, this study provides further proof on the continued validity of the Law of One Price and methodologically for the use of lineal cointegration to analyze horizontal spatial transmission and market integration in the context of international commodity markets. It also provides an example of robust econometrical analysis in controlling structural breaks under cointegration.

Further research is required on the dynamics of price leadership, in order to provide empirical proof on the reasons behind the observed results. In addition, the use of recent innovations in econometrical studies, such as threshold models that reveal arbitrage prices and assymetrical transmission, could provide further proof and insight into the results found here. Finally, applying the methodology used here to higher-frequency data samples, i.e. daily or weekly prices, can help improve on the robustness of results for cointegration analysis.

\section{Acknowledgements}

I thank Prof. Nie Fengying for her guidance as supervisor in The Graduate School of the Chinese Academy of Agricultural Sciences. This work was supported by the Chinese Scholarship Council.

\section{References}

Ardeni, P. G. (1989). Does the law of one price really hold for commodity prices? American Journal of Agricultural Economics, 71(3), 661. https://doi.org/10.2307/1242021

Christofoletti, M. A. M., Silva, R. M., \& Mattos, F. (2012). The increasing participation of China in the world soybean market and its impact on price linkages in futures markets. Proceedings of the NCCC-134 Conference on Applied Commodity Price Analysis, Forecasting, and Market Risk Management. St. Louis, MO. Retrieved from https://ageconsearch.umn.edu/record/285779

Clarke, J. A., \& Mirza, S. (2006). A comparison of some common methods for detecting Granger noncausality. Journal of Statistical Computation and Simulation, 76(3), 207-231. https://doi.org/10.1080/1062936 0500107741

Dawson, P. J., \& Sanjuan, A. I. (2006). Structural breaks, the export enhancement program and the relationship between Canadian and US hard wheat prices. Journal of Agricultural Economics, 57(1), 101-116. https://doi.org/10.1111/j.1477-9552.2006.00034.x

Dawson, P. J., Sanjuán, A. I., \& White, B. (2006). Structural breaks and the relationship between barley and wheat futures prices on the London International Financial Futures Exchange. Review of Agricultural Economics, 28(4), 585-594. https://doi.org/10.1111/j.1467-9353.2006.00324.x

Dolado, J. J., \& Lütkepohl, H. (1996). Making wald tests work for cointegrated VAR systems. Econometric Reviews, 15(4), 369-386. https://doi.org/10.1080/07474939608800362

Fackler, P. L., \& Goodwin, B. K. (2001). Chapter 17 Spatial price analysis. Handbook of Agricultural Economics, 971-1024. https://doi.org/10.1016/S1574-0072(01)01008-8

Garbade, K. D., \& Silber, W. L. (1983). Price movements and price discovery in futures and cash markets. The Review of Economics and Statistics, 65(2), 289. https://doi.org/10.2307/1924495

Gregory, A. W., \& Hansen, B. E. (1996). Residual-based tests for cointegration in models with regime shifts. 
Journal of Econometrics, 70(1), 99-126. https://doi.org/10.1016/0304-4076(69)41685-7

Gregory, A. W., \& Hansen, B. E. (2009). Practitioners corner: Tests for cointegration in models with regime and trend shifts. Oxford Bulletin of Economics and Statistics, 58(3), 555-560. https://doi.org/10.1111/ j.1468-0084.1996.mp58003008.x

Han, L., Liang, R., \& Tang, K. (2013). Cross-market soybean futures price discovery: Does the Dalian Commodity Exchange affect the Chicago Board of Trade? Quantitative Finance, 13(4), 613-626. https://doi.org/10.1080/14697688.2013.775477

Johansen, S. (1995). Likelihood-based inference in cointegrated vector autoregressive models. https://doi.org/ 10.1093/0198774508.001.0001

Lee, K., Lin, C., \& Liao, T. L. (2013). The effect of structural change on information flow between the US and Chinese agricultural futures markets. The Chinese Economy, 46(4), 25-48. https://doi.org/10.2753/ CES1097-1475460402

Li, C., \& Hayes, D. J. (2016). Price discovery on the international soybean futures markets: A threshold co-integration approach. Journal of Futures Markets, 37(1), 52-70. https://doi.org/10.1002/fut.21794

Listorti, G., \& Esposti, R. (2012). Horizontal price transmission in agricultural markets: Fundamental concepts and open empirical issues. Bio-based and Applied Economics, 1(1), 81-108.

Liu, B. J., Wang, Y., Wang, J., Wu, X., \& Zhang, S. (2015). Is China the price taker in soybean futures? China Agricultural Economic Review, 7(3), 389-404. https://doi.org/10.1108/CAER-10-2014-0104

Machado, E. L., \& Margarido, M. A. (2001). Seasonal price transmission in soybean international market: the case of Brazil and Argentina. Pesquisa \& Debate, 12(19), 92-106.

Machado, E. L., \& Margarido, M. A. (2004). Evidence of seasonal price transmission in the soybean international market. Economia Aplicada. Brazilian Journal of Applied Economics, 8(1).

Margarido, M. A., Turolla, F. A., \& Bueno, C. R. (2004). The world market for soybeans: Price transmission into Brazil and effects from the timing of crop and trade. SSRN Electronic Journal. https://doi.org/10.2139/ ssrn.616104

Pippenger, J., \& Phillips, L. (2008). Some pitfalls in testing the law of one price in commodity markets. Journal of International Money and Finance, 27(6), 915-925. https://doi.org/10.1016/j.jimonfin.2008.05.003

Ravallion, M. (1986). Testing market integration. American Journal of Agricultural Economics, 68(1), 102. https://doi.org/10.2307/1241654

Said, S. E., \& Dickey, D. A. (1984). Testing for unit roots in autoregressive-moving average models of unknown order. Biometrika, 71(3), 599. https://doi.org/10.1093/biomet/71.3.599

Toda, H. Y., \& Phillips, P. C. (1994). Vector autoregression and causality: A theoretical overview and simulation study. Econometric Reviews, 13(2), 259-285. https://doi.org/10.1080/07474939408800286

Toda, H. Y., \& Yamamoto, T. (1995). Statistical inference in vector autoregressions with possibly integrated processes. Journal of Econometrics, 66(1-2), 225-250. https://doi.org/10.1016/0304-4076(94)01616-8

Uri, N. D., Chomo, G., Hoskin, R., \& Hyberg, B. (1993). The integration of the market for soybeans and soybean products. Food Policy, 18(3), 200-213. https://doi.org/10.1016/0306-9192(93)90077-O

USDA (United States Department of Agriculture). (1999-2019). Oilseeds: World markets and trade.

Zapata, H. O., \& Rambaldi, A. N. (1997). Monte Carlo evidence on cointegration and causation. Oxford Bulletin of Economics and Statistics, 59(2), 285-298. https://doi.org/10.1111/1468-0084.00065

Zivot, E., \& Andrews, D. W. (1992). Further evidence on the great crash, the oil-price shock, and the unit-root hypothesis. Journal of Business \& Economic Statistics, 10(3), 251. https://doi.org/10.2307/1391541

\section{Copyrights}

Copyright for this article is retained by the author(s), with first publication rights granted to the journal.

This is an open-access article distributed under the terms and conditions of the Creative Commons Attribution license (http://creativecommons.org/licenses/by/4.0/). 